\title{
Prevalence of Premalignant and Malignant Cervical Lesions among Patients by Visual Inspection with Acetic Acid (VIA) in a Tertiary Care Hospital in Bangalore- An Observational Study
}

\author{
Jagruthi C. ${ }^{1}$, Hemavathi G. ${ }^{2}$ \\ 1DNB Resident, Department of Obstetrics and Gynaecology, Bangalore Baptist Hospital, Bangalore, Karnataka, India. \\ ${ }^{2}$ Senior Resident, Department of Obstetrics and Gynaecology, Koppal Institute of Medical Sciences, Koppal, Karnataka, \\ India.
}

\section{ABSTRACT}

\section{BACKGROUND}

Cervical cancer continues to be a major public health problem in India in the absence of widespread organized cervical screening programs. Visual inspection of the cervix with acetic acid (VIA) is an effective, inexpensive screening test that can be combined with simple treatment procedures for early cervical lesions, provided by trained health workers. We report 2 years' experience in early detection of cervical cancer and pre-cancers using the VIA test in a tertiary care hospital in Bengaluru, India. We wanted to study the prevalence of malignant and premalignant cervical lesions by VIA with acetic acid in Bangalore Baptist Hospital, Bangalore and study the demographic factors associated with malignant and premalignant lesions of cervix among the same population.

\section{METHODS}

This is a cross-sectional study. Eligible women aged between 20 years (sexually active) and 60 years were screened using the VIA test for 2 years. Women who tested positive were further evaluated by taking punch biopsy.

\section{RESULTS}

A total of 516 women were screened by a single round of VIA testing with a positive rate of $11.2 \%$ and $3.5 \%$ were biopsy positive. Out of 516 women, VIA was positive in 58 cases $(11.2 \%)$. Biopsy done in 57 cases and biopsy was positive in 18 cases (3.5\%). Biopsy reports showed 9 women with squamous cell carcinoma, 1 with adenocarcinoma, 1 with CIN1, 3 with CIN3, 4 with koilocytic atypia. Positive predictive value for VIA is $30 \%$. Prevalence of premalignant and malignant lesions of cervix is $3.5 \%$.

\section{CONCLUSIONS}

Our study reports experience of implementing VIA based cervical screening method in patients attending gynaecology OPD in a tertiary care hospital. VIA is a simple and affordable screening test with acceptable sensitivity and specificity in the range of $50-88.6 \%$ and $66.7-89.7 \%$ respectively. These results have important implications for efficient service delivery in cervical screening programs in low resource settings.

\section{KEY WORDS}

Cervical Cancer Screening, Cervical Screening in Low Resource Settings, Early Detection of Cervical Cancer, Malignant and Premalignant Lesions, Visual Inspection with Acetic Acid (VIA)
Corresponding Author:

Dr. Jagruthi $C$.,

DNB Resident, Department of OBG,

Bangalore Baptist Hospital,

Bangalore, Hebbal, Karnataka, India

E-mail: cjagruthi08@gmail.com

DOI: $10.14260 / \mathrm{jemds} / 2019 / 598$

Financial or Other Competing Interests: None.

How to Cite This Article:

Jagruthi C, Hemavathi G. Prevalence of premalignant and malignant cervical lesions among patients by visual inspection with acetic acid (via) in a tertiary care hospital in Bangalore- an observational study. J. Evolution Med. Dent. Sci. 2019;8(35):2758-2762, $10.14260 /$ jemds $/ 2019 / 598$

Submission 22-06-2019,

Peer Review 14-08-2019,

Acceptance 21-08-2019,

Published 02-09-2019. 


\section{BACKGROUND}

Cancer cervix is the fourth most common cancer in women, and the seventh overall, with an estimated 528,000 new cases in the world and 123,000 new cases in India.[1] In developing countries, there is a lack of effective screening programs for cervical cancer. In these countries no clinically significant reduction in the incidence of cervical cancer has occurred during the past three decades. In developed countries, in contrast, there has been a major decline in cervical cancer mortality after the introduction of large-scale cytological screening. The limited success of such screening in developing countries has stimulated evaluation of testing for Human Papilloma virus (HPV) and Visual inspection with acetic acid (VIA). The association between certain oncogenic (high risk) strains of HPV and cervical cancer is well established. HPV has been implicated in $99.7 \%$ of cervical squamous cell carcinoma cases worldwide.[2] HPV infection has prolonged latent phase. Hence screening methods are necessary for early detection of premalignant lesions of cancer cervix. Screening for cancerous and precancerous changes of cervix has traditionally been performed by pap test. Factors which reduce the efficacy of screening programs in developing countries are lack of funds, expertise, knowledge among people regarding disease screening programs and compliance to treatment.

After analysing the above factors, various studies are being done to see that VIA can be included in screening trial, in developing countries because it is simple, easy to learn approach, minimal infrastructure, low start up and sustaining costs, test results are available immediately, requires only one visit, can be performed at any time during the menstrual cycle, including during menses (Provided flow is not heavy), during pregnancy, at a postpartum examination, or during a post abortion check-ups. It can also be done when a woman comes for care related to STIs, HIV screening or follow up care. [3] VIA has emerged as a promising, cost-effective, noncytology based, "see and treat" alternative for economically underprivileged geographical regions. ${ }^{[4]}$ Limitations of VIA are false positive rates and resources being spent on unnecessary treatment of women who are free of precancerous lesions in a single visit approach. ${ }^{[5]}$

We wanted to determine the prevalence and the associated demographic factors for premalignant and malignant lesions of cervix by VIA among patients visiting gynaecology OPD in a tertiary care hospital. If VIA has a proven approach in screening cervical cancers it can be used further to screen patients as a replacement for pap smear or in addition to pap smear in a simple cost-effective manner.

\section{METHODS}

\section{Study Setting}

This is a cross sectional study which includes women attending the outpatient department of Bangalore Baptist Hospital, Bangalore for 2 years.

\section{Sample Size}

According to Globocan 2012 statistics, there are 123 per 1000 new cases of cancer cervix in India. The sample size is calculated based on this data and the sample size is 685 .

Sample size $n=\left[D E F F^{*} N p(1-p)\right] /\left[\left(d^{2} / Z^{2}{ }_{1-\alpha / 2} *(N-1)+p^{*}(1-p)\right]\right.$

\begin{tabular}{|}
\begin{tabular}{|c|c|}
\hline Population size (for finite population correction factor or fpc) (N): & 1000000 \\
\hline Hypothesized \% frequency of outcome factor in the population (p): & $12.3 \%+/-2.46$ \\
\hline Confidence limits as \% of 100(absolute $+/-\%)(\mathrm{d}):$ & $2.46 \%$ \\
\hline Design effect (for cluster surveys-DEFF): & 1 \\
\hline \multicolumn{2}{|c|}{ Sample Size Calculation } \\
\hline \multicolumn{2}{|c|}{} \\
\hline Confidence Level (\%) & Sample Size \\
\hline $95 \%$ & 685 \\
\hline $80 \%$ & 293 \\
\hline $90 \%$ & 483 \\
\hline $97 \%$ & 839 \\
\hline $99 \%$ & 1182 \\
\hline $99.9 \%$ & 1927 \\
\hline $99.99 \%$ & 2692 \\
\hline Sample Size (n) for Various Confidence Levels \\
\hline
\end{tabular}
\end{tabular}

\section{Inclusion Criteria}

Women of age group 20 years (Sexually active) to 60 years including pregnant women.

\section{Exclusion Criteria}

1. Patients with active vaginal infection.

2. Patients with menstrual bleeding.

3. Patients with macroscopic cervical lesions.

\section{Study Principle}

VIA is based on principle that acetic acid coagulates the proteins of nucleus and cytoplasm and makes the proteins opaque and white.

\section{Methodology}

Questionnaire which includes age, socioeconomic status, symptoms, menstrual history, age of menarche, age of marriage, age of first coitus, age of first pregnancy, no. of sexual partners, age of menopause(if attained), any previous pap smear reports if available.

\section{Visual Inspection after Acetic Acid Test}

The procedure and the reason for it will be carefully explained to the woman to be examined and she will be made as comfortable as possible taking into consideration the privacy of the patient. Patient will be put in lithotomy position (If possible) or dorsal position. The light source will be directed to the genital area. Any abnormal findings in the external genitalia will be observed and recorded. The speculum will be lubricated with warm water and inserted into the vagina with the speculum closed. The speculum will be opened, and the light source adjusted so as to get a clear view of the cervix. If there is excess mucus or discharge, it will be cleared with a cotton swab soaked in boiled water or normal saline solution. Findings will be observed and recorded. The cervix will be wiped with a cotton swab dipped in normal saline followed by application of 3-5\% acetic acid dipped in another cotton swab to the cervix and will be waited for approximately 2 minutes. The cervix is inspected for acetowhite areas. The squamocolumnar junction is located. 


\section{Criteria for Positive VIA}

Appearance of well-defined densely opaque acetowhite lesions in the transformation zone close to squamocolumnar junction or external os. Anything that doesn't meet the criteria for a positive test including. Absence of acetowhite lesion- Faint or ill-defined translucent acetowhite areas. Faint acetowhitening of endocervical polyps. Nabothian cysts. Dot like acetowhite appearance. Will be categorised negative. Since VIA has high Negative predictive value and Specificity, all VIA negative cases are considered biopsy negative in our study.

\section{Statistical Analysis}

The statistical software namely SPSS 16.0 were used for the analysis of the data and Microsoft word and excel have been used to generate graphs, tables etc.

\section{Ethics}

The study procedure will be explained to all women and written informed consent will be taken from them. The patients will not be charged any additional amount for the study. Patient's medical information (Personal details, results of physical examinations, investigations and medical history) will be maintained confidentially. Patient's decision not to participate in this research study will not affect medical care or relationship with the investigator or the institution.

\section{RESULTS}

\begin{tabular}{|c|c|c|}
\hline Age & Frequency & Percent \\
\hline $20-30$ & 76 & 14.7 \\
\hline $31-40$ & 164 & 31.8 \\
\hline $41-50$ & 193 & 37.4 \\
\hline $51-60$ & 83 & 16.1 \\
\hline \multicolumn{2}{|r|}{ Table 1. Age Distribution Frequency Table } \\
\hline
\end{tabular}

Most of the patients are in the age group of $41-50$ years (37.4\%) and 3140 years is $31.8 \%$.

\begin{tabular}{|c|c|c|}
\hline SES & Frequency & Percent \\
\hline Low & 108 & 20.9 \\
\hline Middle & 365 & 70.8 \\
\hline Upper & 43 & 8.3 \\
\hline Total & $\mathbf{5 1 6}$ & $\mathbf{1 0 0 . 0}$ \\
\hline \multicolumn{2}{|c|}{ Table 2. Socio Economic Status Frequency Table } \\
\end{tabular}

Most of the study population belong to middle socioeconomic population that is $363(70.8 \%)$ out of 516 .

\begin{tabular}{|c|c|c|}
\hline AOM & Frequency & Percent \\
\hline $10-20$ & 268 & 51.9 \\
\hline $21-30$ & 245 & 47.5 \\
\hline$>30$ & 3 & 0.6 \\
\hline Total & $\mathbf{5 1 6}$ & $\mathbf{1 0 0 . 0}$ \\
\hline \multicolumn{3}{|c|}{ Table 3. Age of Marriage } \\
\hline $\begin{array}{l}268(51.9 \%) \text { women are married between 10 years and 20 years. 245 } \\
\text { (47.5\%) are married between 21 and 30 years. 3 (0.6\%) women are } \\
\text { married after 30 years }\end{array}$ \\
\hline
\end{tabular}

\begin{tabular}{|c|c|c|}
\hline Symptoms & Frequency & Percent \\
\hline Backache & 13 & 2.5 \\
\hline Dysmenorrhea & 6 & 1.2 \\
\hline Dyspareunia & 4 & 0.8 \\
\hline health plan & 104 & 20.2 \\
\hline HMB & 45 & 8.7 \\
\hline Intermenstrual bleeding & 5 & 1.0 \\
\hline Mass per vaginum & 4 & 0.8 \\
\hline Menstrual irregularities & 42 & 8.1 \\
\hline Pain abdomen & 36 & 7.0 \\
\hline
\end{tabular}

\begin{tabular}{|c|c|c|}
\hline PMB & 23 & 4.5 \\
\hline postcoital bleeding & 7 & 1.4 \\
\hline Routine check up & 52 & 10.1 \\
\hline RV positive routine pap smear & 56 & 10.9 \\
\hline Urinary complaints & 14 & 2.7 \\
\hline WDPV & 105 & 20.3 \\
\hline Total & $\mathbf{5 1 6}$ & $\mathbf{1 0 0 . 0}$ \\
\hline \multicolumn{2}{|c|}{ Table 4. Symptoms }
\end{tabular}

Patients presented with varied symptoms. Majority of population were screened in health plan $(20.2 \%)$. majority of population presented with white discharge per vaginum $(20.2 \%)$.

\begin{tabular}{|c|c|c|}
\hline Previous Pap Smear & Frequency & Percent \\
\hline Done- Abnormal & 8 & 1.6 \\
\hline Done - Normal & 57 & 11 \\
\hline Not done & 451 & 87.4 \\
\hline Total & $\mathbf{5 1 6}$ & $\mathbf{1 0 0 . 0}$ \\
\hline \multicolumn{2}{|c|}{ Table 5. Previous Pap Smear } \\
\hline
\end{tabular}

Pap smears were not done in majority of population (87.4\%). It was done in $12.6 \%$ of women. $11 \%$ of pap smears were normal reports and $1.6 \%$ were abnormal reports

\begin{tabular}{|c|c|c|}
\hline Cervix (Per Speculum) & Frequency & Percent \\
\hline Abnormal & 24 & 5 \\
\hline Erosion & 61 & 12 \\
\hline Hypertrophied cervix & 19 & 4 \\
\hline Infection+ & 31 & 6 \\
\hline Normal & 381 & 73 \\
\hline Total & $\mathbf{5 1 6}$ & $\mathbf{1 0 0 . 0}$ \\
\hline \multicolumn{2}{|c|}{ Table 6. Cervix (Per speculum) }
\end{tabular}

Majority had normal appearing cervix on per speculum examination. Abnormal cervix seen in $5 \%$ of population.

\begin{tabular}{|c|c|c|c|c|c|}
\hline SES & $\begin{array}{c}\text { Biopsy } \\
\text { Negative }\end{array}$ & $\begin{array}{c}\text { Biopsy } \\
\text { Positive } \\
\end{array}$ & Total & \begin{tabular}{|c|}
$\begin{array}{c}\text { Chi-Square } \\
\text { Value }\end{array}$ \\
\end{tabular} & p-Value \\
\hline $\mathrm{L}$ & $97(19.4)$ & $11(61)$ & 108 & \multirow{4}{*}{18.248} & \multirow{4}{*}{.000} \\
\hline $\mathrm{M}$ & $359(72)$ & $6(33)$ & 365 & & \\
\hline $\mathrm{U}$ & $42(8.6)$ & $1(6)$ & 43 & & \\
\hline Total & 498 & 18 & 516 & & \\
\hline \multicolumn{6}{|c|}{ Table 7. SES * Biopsy } \\
\hline
\end{tabular}

\begin{tabular}{|c|c|c|c|c|c|}
\hline Age Group & $\begin{array}{c}\text { Biopsy } \\
\text { Negative }\end{array}$ & $\begin{array}{c}\text { Biopsy } \\
\text { Positive } \\
\end{array}$ & Total & \begin{tabular}{|c|}
$\begin{array}{c}\text { Chi-Square } \\
\text { Value }\end{array}$ \\
\end{tabular} & p-Value \\
\hline $20-30$ & $76(15)$ & $0(0)$ & 76 & \multirow{5}{*}{5.660} & \multirow{5}{*}{0.129} \\
\hline $31-40$ & $160(32)$ & $4(22)$ & 164 & & \\
\hline $41-50$ & $184(37)$ & $9(50)$ & 193 & & \\
\hline $51-60$ & $78(16)$ & $5(28)$ & 83 & & \\
\hline Total & 498 & 18 & 516 & & \\
\hline \multicolumn{6}{|c|}{ Table 8. Age Group * Biopsy } \\
\hline
\end{tabular}

Majority of biopsy positive cases were in between $41-50$ years (50\%), and between $31-40$ years (28\%).

\section{DISCUSSION}

This is a cross sectional study done in Bangalore Baptist hospital during 2016 to 2018. The current study was designed to know the effectiveness of alternatives to cytologic screening for detecting high grade SIL and invasive carcinoma in a resource poor setting. Visual screening methods recently received considerable attention as alternatives to cytologic screening in resource-poor settings. They are perceived as requiring a lower level of infrastructure and as being less expensive than cytologic screening because they do not require cytology laboratories with their attendant training and quality control costs. Visual methods provide an immediate result that is preferable in settings in which transportation facilities are minimal, in which it is difficult to track women with abnormal test results, or in which women must travel for long distances to health care facilities. 


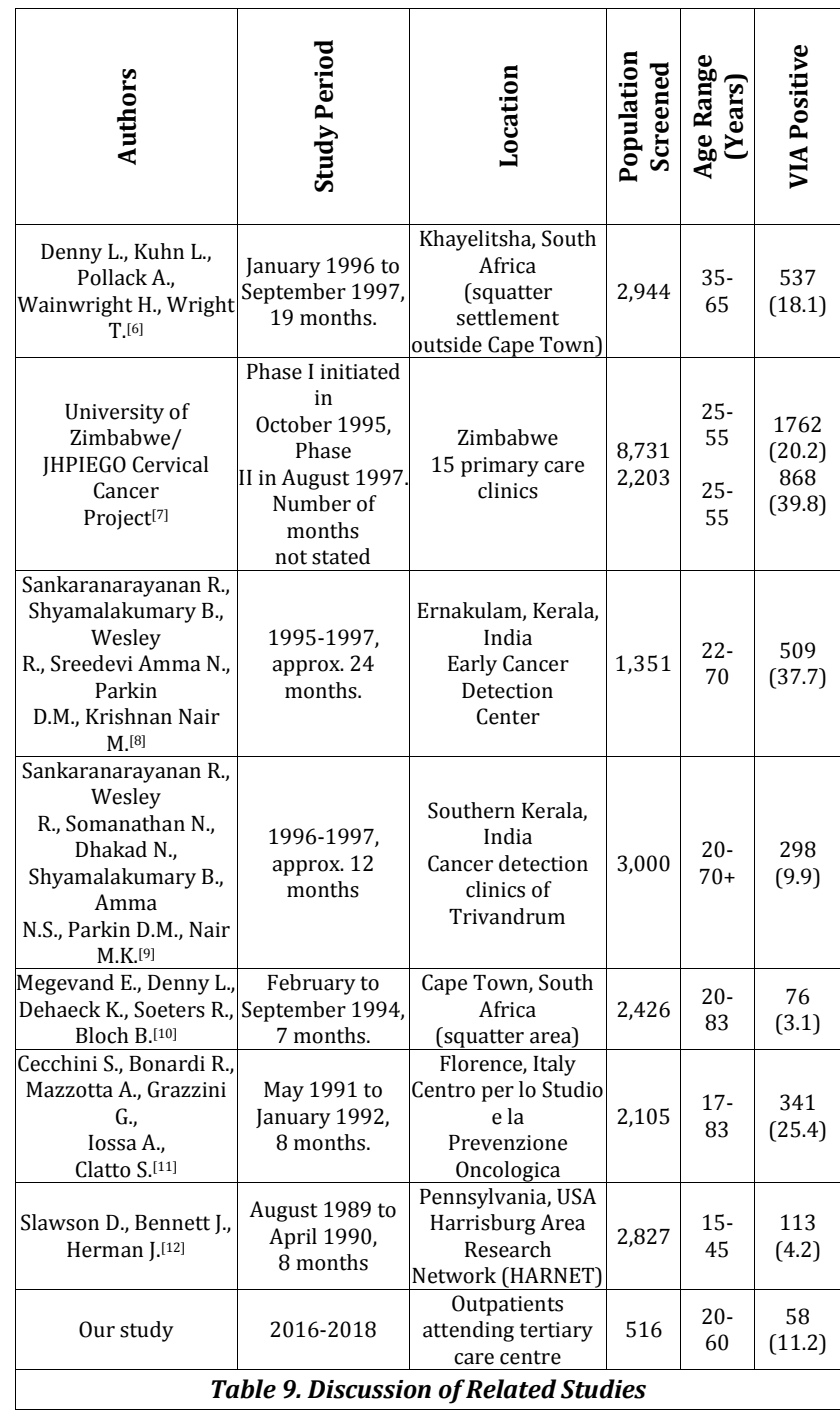

In our study among the screened population of 518 women, 58 are screened positive by VIA. Biopsy done in 57 women, among them 18 are positive for premalignant and malignant lesions of cervix. The biopsy reports show 9 women with Squamus cell carcinoma, 1 with adenocarcinoma, 1 with CIN-1, 3 with CIN-3, 4 with koilocytic atypia. Hence the positive predictive predictive value is $3.5 \%$ which is comparable with other studies. According to Sankarnarayanan et al[8] a single good quality VIA screen has a sensitivity around $40-50 \%$, specificity around $80-90 \%$ and a positive predictive value around $5-10 \%$ for detecting high grade CIN. A negative VIA has a high negative predictive value. A single round of VIA screening has been shown to reduce cervical carcinoma incidence by $25 \%$ and mortality by $35 \%$ in a randomized controlled trial in India. In another randomized trial in South Africa VIA screen and treat strategy led to a $35 \%$ reduction in cervical precancerous lesions. World Health Organization recommends VIA screening as one of the best buys for cancer control.

\section{CONCLUSIONS}

Our study reports experience of implementing VIA based cervical screening method in patients attending OPD in a tertiary care hospital. VIA is a simple and affordable screening test with acceptable sensitivity and specificity in the range of $50-88.6 \%$ and $66.7-89.7 \%$ respectively. Our study results show that the screen positivity is $11.2 \%$ and the detection rate of premalignant and malignant lesions of cervix is $3.5 \%$. This is comparable with other research studies on VIA where positivity ranged from $6.6 \%$ to $27.4 \%$. Early age of marriage (10-20 years), low socioeconomic status, abnormal cervix in per speculum examination, the cervix which bleeds on touch and hard consistency are significant risk factors in history and examination for malignant and premalignant lesions of cervix as described by other studies as well. The prevalence of malignant and premalignant lesions of carcinoma cervix is $3.5 \%$ in our study as we have screened the symptomatic patients attending OPD in a tertiary care hospital unlike community-based screening programs. Hence VIA can be taken as effective screening method in countries with limited resources or in situations when such screening is not available as it is an inexpensive and easy alternative that can be performed by non-medical health workers with considerable sensitivity and specificity which is similar to cytology.

\section{REFERENCES}

[1] Globocan 2012 statistics. [Cited 2016 July 15]. http://globocan.iarc.fr/Pages/fact_sheets_cancer.aspx

[2] Burd EM. Human papillomavirus and cervical cancer. Clinical Microbiology Reviews 2003;16(1):1-17.

[3] Sarian LO, Derchain SF, Naud P, et al. Evaluation of visual inspection with acetic acid (VIA), Lugol's iodine (VILI), cervical cytology and HPV testing as cervical screening tools in Latin America: This report refers to partial results from the LAMS (Latin AMerican Screening) study. J Med Screen 2005;12(3):142-9.

[4] Longatto-Filho A, Naud P, Derchain SF, et al. Performance characteristics of Pap test, VIA, VILI, HRHPV testing, cervicography and colposcopy in diagnosis of significant cervical pathology. Virchows Arch 2012;460(6):577-85.

[5] Torre LA, Bray F, Siegel RL, et al. Global cancer statistics, 2012. CA: Cancer J Clin 2015;65(2):87-108.

[6] Denny L, Kuhn L, Pollack A, et al. Evaluation of alternative methods of cervical cancer screening for resource-poor settings. Cancer 2000;89(4):826-33.

[7] Gaffikin L, Bluementhal PD, McGrath J, et al. University of Zimbabwe JHPIEGO cervical Cancer project. Visual inspection with acetic acid for cervical cancer screening. Test qualities in a primary care setting. Lancet 1999;353(9156):869-73.

[8] Sankaranarayanan R, Shyamalakumary B, Wesley R, et al. La inspección visual con ácido acético en la detección precoz del cáncer cervicouterino y sus precursores. Inspección Visual Del Cuello Uterino Con Ácido Acético (IVAA): 47. 
[9] Sankaranarayanan R, Wesley R, Somanathan T, et al. La inspección visual del cuello uterino tras la aplicación de ácido acético en la detección del carcinoma cervicouterino y sus precursores. Inspección Visual Del Cuello Uterino Con Ácido Acético (IVAA): 51.

[10] Megevand E, Denny L, Dehaeck K, et al. Acetic acid visualization of the cervix: an alternative to cytologic screening. Obstet Gynecol 1996;88(3):383-6.
[11] Ferreccio C, Gage J. Visual inspection of the uterine cervix with Acetic Acid (VIA): a critical review and selected articles. Pan American Health Organization: 2003.

[12] Slawson DC, Bennett JH, Herman JM. Are Papanicolaou smears enough? Acetic acid washes of the cervix as adjunctive therapy: a HARNET study. Journal of Family Practice 1992;35(3):271-7. 